\title{
Age-related differences in injury pattern and hospital stay after paediatric trauma
}

\author{
HQ Do ${ }^{1,2^{*}}$, J Steinmetz ${ }^{1,2}$, LS Rasmussen ${ }^{1}$ \\ From London Trauma Conference \\ London, UK. 22-24 June 2011
}

\section{Introduction}

It is estimated that children account for around $10 \%$ of all trauma admissions. While few studies describe paediatric trauma, only one British study has described age-related differences after paediatric trauma [1].

\section{Aim}

To describe age-related differences in paediatric trauma patients admitted to a Danish level 1 trauma center.

\section{Methods}

We included 331 paediatric trauma patients admitted during the 9-year period 1999-2007. Subjects were studied with respect to four age groups $(<1$ year $[n=20], 1-5$ years $[n=119], 6-10$ years $[n=72]$, and $11-15$ years $[n=120])$. We analysed the groups with regard to injury type and mechanism, injury severity score (ISS), and length of stay. $\mathrm{p}<0.05$ was considered statistically significant.

\section{Results}

Injury type and mechanism were significantly different between the four groups $(\mathrm{p}<0.0001)$. The leading cause of trauma were burn injuries (65\%) in patients aged less than 1 year, burn injuries (49\%) and blunt trauma (49\%) in children between 1-5 years, and blunt trauma $(81 \% /$ $82 \%)$ in 6-10 and 11-15 year old children. Mechanisms of blunt trauma were mainly road traffic accidents, followed by fall accidents. In total, eight (2\%) patients had penetrating trauma.

ISS increased with age, however not significantly $(\mathrm{p}=0.19)$, median ISS $9,9,10$, and 11 respectively.

With increasing age, a significant decline in total length of stay was observed, median 20,15, 9, and 9 days respectively $(\mathrm{p}=0.005)$. However, patients aged 6 or more had a significantly longer stay at the ICU, median $0,0,1$, and 1 day respectively $(\mathrm{p}=0.002)$.

\section{Conclusions}

Burn injuries were the leading cause of trauma in children aged less than 1 year, while burn injuries and blunt trauma occurred equally in 1-5 year old children. Children older than 6 years were more often implicated in blunt trauma, predominantly road traffic accidents and fall accidents. This age-related difference in injury pattern was reflected in the total length of stay that decreased with advancing age.

\section{Author details}

'Department of Anaesthesia, Centre of Head and Orthopaedics, Copenhagen University Hospital, Rigshospitalet, Denmark. ${ }^{2}$ Trauma Centre \& Acute Admissions, Centre of Head and Orthopaedics, Copenhagen University Hospital, Rigshospitalet, Denmark.

Published: 22 March 2012

\section{Reference}

1. Bayreuther J, Wagener S, Woodford M, Edwards A, Lecky F, Bouamra O, Dykes E: Pediatric trauma: injury pattern and mortality in the UK. Arch Dis Child Educ Pract Ed 2009, 94:37-41.

\section{doi:10.1186/1757-7241-20-S1-O8}

Cite this article as: Do et al.: Age-related differences in injury pattern and hospital stay after paediatric trauma. Scandinavian Journal of

Trauma, Resuscitation and

Emergency Medicine 2012 20(Suppl 1):08. 